\title{
Subjetividade em correção de redações: deteç̧ão automática através de léxico de operadores de viés linguístico
}

Subjectivity in essay grading: automatic detection through language bias operator lexicon

\author{
Márcia Cançado () \\ FALE/Univ.Federal de Minas Gerais \\ mcancado@ufmg.br \\ Evelin Amorim (1) \\ DCC/Univ. Federal de Minas Gerais \\ evelin.amorim@gmail.com
}

\author{
Luana Amaral (10) \\ FALE/Univ. Federal de Minas Gerais \\ luanalopes@ufmg.br \\ Adriano Veloso (1) \\ DCC/Univ. Federal de Minas Gerais \\ adrianov@dcc.ufmg.br
}

\author{
Heliana Mello \\ FALE/Univ. Federal de Minas Gerais \\ heliana.mello@gmail.com
}

\section{Resumo}

As redações são instrumentos avaliativos muito importantes para os estudantes brasileiros. Mesmo que seja assumido que a subjetividade esteja presente em todo e qualquer texto, espera-se que as correções dessas redações sejam feitas com o mínimo de subjetividade possível. Entretanto, a partir da análise de uma amostra de correções de redação, percebemos um alto grau de subjetividade nesses textos. Baseados nessa pré-análise, feita de forma manual, levantamos a hipótese de que o gênero "correção de redação" é mais subjetivo do que se esperaria. Para corroborar essa hipótese, elaboramos uma lista de operadores linguísticos, marcadores de viés, dividida em quatro categorias: operadores argumentativos, operadores de pressuposição, operadores de modalidade e operadores de opinião e valoração. Essa lista foi aplicada, através de uma metodologia de detecção automática de linguagem enviesada, a um corpus de correções de redação. A partir disso, quantificamos os operadores de viés presentes nesses textos. Foram também analisados esses operadores de viés em dois outros corpora: de resumos acadêmicos e de resenhas de produtos publicadas em sites de vendas na internet. A ideia dessa análise foi compararmos a distribuição dessas marcas de viés nas correções de redação e em gêneros reconhecidamente menos subjetivos (resumos acadêmicos) e reconhecidamente mais subjetivos (resenhas). Para tal comparação, lançamos mão de uma ferramenta estatística muito utilizada na análise de comparação de dados, os boxplots. Os nossos resultados mostraram que a distribuição de operadores de viés linguístico nas correções de redação se aproxima mais da distribuição desses itens em resenhas do que em resumos acadêmicos. Isso corrobora nossa hipótese e indica que o grau de subjetividade das correções é alto, estando mais próximo do grau de subjetividade de um texto como as resenhas. Concluímos, portanto, que essas correções refletem pontos de vista do corretor, que se afastam dos critérios de correção, o que coloca dúvidas sobre a consideração desse gênero como um instrumento avaliador isento e justo.

\section{Palavras chave}

correção de redação, subjetividade, léxico de operador de viés, detecção automática

\section{Abstract}

Essays are very important assessment tools for Brazilian students. Therefore, it is expected that the grading of these texts will be made with as little subjectivity as possible. However, in an analysis of a sample of grading sheet comments by evaluators, we have noticed a high degree of subjectivity in these texts. From this first analysis, carried manually, we proposed the hypothesis that this genre is more subjective than one would expect. In order to corroborate this hypothesis, we have drawn up a list of linguistic bias markers, divided into four categories: argumentative operators, presupposition operators, modalization operators, and opinion and value operators. This list was applied to a corpus of essay grading sheet comments by evaluators, using an automatic language bias detection methodology. From this, we were able to quantify the linguistic bias markers present in these texts. These bias markers were also analyzed in two other corpora: abstracts and product reviews published on internet sales sites. We have compared the percentage of these markers in 
evaluators' comments with the percentage numbers of these markers in genres admittedly less subjective (abstracts) and admittedly more subjective (reviews). For such comparison, we have used boxplots, a statistical tool widely used in data comparison analysis. Our results indicated that the grading sheets, as for the number of bias markers, are closer to more subjective texts than to less subjective texts. This corroborates our hypothesis and indicates that these grading sheets present a high degree of subjectivity, closer to the degree of a more subjective text. Thus, we conclude that these grading sheets reflect the personal views of the evaluator, deviating from the correction criteria, which raises doubts about considering this genre an exempt and fair assessment instrument.

\section{Keywords}

essay grading, subjectivity, bias operator lexicon, automatic detection

\section{Introdução}

Seguindo a linha teórica da Semântica Argumentativa, Anscombre \& Ducrot (1976) e Ducrot (1987) (e trabalhos subsequentes) afirmam que há pistas na língua que indicam uma orientação, ou um viés, do locutor. Essas pistas podem ser detectadas por operadores argumentativos, tipos específicos de verbos, modalizadores e outras expressões linguísticas. A distribuição numérica dessas marcas no texto pode indicar graus de subjetividade, o que chamamos aqui de "viés linguístico". Mesmo que seja assumido que a subjetividade esteja presente em todo e qualquer texto, ainda assim, é possível fazer distinções de grau e, ainda mais, é possível detectar a orientação de textos muito marcados nesse sentido.

Tendo em vista essa afirmação, espera-se que um texto como a correção de uma redação não apresente um alto índice de viés linguístico. Essa expectativa deve-se ao fato de que, primeiramente, a redação é usada como um instrumento avaliativo durante toda a trajetória de formação escolar de um estudante do ensino básico; e, um segundo fato, de grande relevância, é que redações são amplamente utilizadas como instrumento de classificação em concursos importantes, realçando, no Brasil, a utilização desse procedimento no ENEM (Exame Nacional do Ensino Médio). Neste último caso, a nota da redação é a responsável por uma grande parte da classificação de um candidato, fechando ou abrindo as portas de entrada em nossas universidades públicas. Por isso, espera-se que esse instrumento de avaliação seja o mais isento possível de qualquer tipo de viés do corretor, não apresentando, assim, desigualdades nos resultados.
Neste artigo, propomos que o grau de viés linguístico apresentado pelo corretor de redações pode ser detectado por pistas linguísticas nos textos dessas correções. Analisamos, preliminarmente, uma amostra de 50 exemplares do gênero. Identificamos, manualmente, a partir do nosso conhecimento teórico e da nossa intuição de falantes do português, marcas linguísticas de subjetividade nesses textos. Os resultados dessa primeira análise indicaram o oposto do esperado: encontramos correções com um número alto de operadores linguísticos marcadores de viés. Além disso, ao fazermos nós mesmos a correção das redações, percebemos que as notas que se distanciavam muito das notas atribuídas por nós, seja para cima ou para baixo, eram acompanhadas de justificativas muito subjetivas, segundo critérios preliminares que estabelecemos. Dessa forma, chegamos à hipótese de que o gênero correção de redação não é tão isento de subjetividade quanto se esperaria e esses textos, sendo permeados de marcas de viés linguístico, indicam também um viés do corretor na correção de redações.

Na mesma linha da nossa hipótese, Mendes (2013), em seu artigo sobre a subjetividade na avaliação de redações, demonstra a inviabilidade de se manter tal tipo de prova em processos seletivos, dada a impossibilidade de se fazer justiça aos candidatos. A pesquisadora aponta que nos próprios critérios usados na correção do ENEM "encontram-se evidências do problema da subjetividade na descrição dos níveis das competências. Como se poderá verificar, esses descritores são eivados de modalizadores, apresentam vagueza conceitual e termos obscuros" (Mendes (2013), p. 439). A autora apresenta, ainda, uma pesquisa empírica sobre o sistema de avaliações de redações no ENEM, em que ela e mais um grupo de docentes e alunos de pós-graduação corrigiram 700 redações feitas por alunos de um curso pré-vestibular. Essa correção foi feita seguindo os mesmos critérios e sistemática de correção do ENEM. A partir dessa pesquisa empírica, o artigo apresenta interessantes resultados, como a discrepância entre as notas atribuídas pelos avaliadores, a discrepância entre as notas dependendo do horário da correção e até mesmo diferenças em notas atribuídas a uma mesma redação por um mesmo corretor, em momentos diferentes. A autora aponta que, além da subjetividade intrínseca ao próprio avaliador, outros fatores também subjetivos interferem na confiabilidade da avaliação, como o perfil do avaliador, a sua tolerância ao cansaço, a interação entre avaliadores e erros na avaliação. 
Para provarmos essa hipótese de forma mais rigorosa, neste trabalho, nos valemos de uma metodologia de análise usada na Linguística Computacional, chamada de "deteç̧ão automática de linguagem enviesada" (Recasens et al., 2013). A proposta dessa metodologia é que, a partir de um trabalho manual de análise linguística feita por falantes nativos para o entendimento da realização dos vieses linguísticos, pode-se propor um detector automático de viés composto de uma lista de palavras indutoras de vieses linguísticos. Assim, elaboramos uma lista de operadores, marcadores de viés linguístico, dividida em quatro categorias: operadores argumentativos, operadores de pressuposição, operadores de modalização e operadores de opinião e valoração. Para a elaboração dessa lista, apoiamo-nos nos pressupostos teóricos da Semântica Argumentativa, principalmente por Anscombre \& Ducrot (1976); Ducrot (1987); Koch (2011, 2015). Apresentamos também, como objetivo do artigo, a elaboração dessa lista de operadores de viés linguístico para o português.

Dando continuidade à nossa pesquisa, extraímos, de forma automática, um corpus de textos do gênero correção de redação, disponíveis no banco de redações do UOL, para procedermos, também de forma automática, à identificação e à contagem dos operadores de viés listados. Mas somente a contagem desses operadores de viés não comprovaria nossa hipótese, já que é consenso na literatura em Linguística Textual que marcas de subjetividade são encontradas em qualquer texto. Então, assumimos uma perspectiva comparativa, partindo do pressuposto de que, entre os vários gêneros textuais, é possível detectar distinções do grau de subjetividade. Assim, comparamos a distribuição dos operadores nas correções de redações com a distribuição dessas marcas em um corpus de resumos acadêmicos (textos com menor grau de subjetividade) e em um corpus de resenhas (textos com maior grau de subjetividade). Nosso propósito, ao fazer tal comparação, é verificar de qual polo de subjetividade as correções mais se aproximam.

Para fazer a comparação entre os três gêneros, utilizamos uma ferramenta gráfica muito usada em estatística na análise de comparação de dados: o boxplot. O resultado que obtivemos é que textos do gênero correção de redação, em relação ao grau de subjetividade, se aproximam mais do comportamento de textos do gênero resenha do que de textos do gênero resumo acadêmico. Consideramos que tal resultado não é o desejado para um gênero textual que deveria apresentar um baixo grau de subjetividade, devendo, a princípio, se aproximar mais dos textos de gêneros acadêmicos. Esse resultado confirma nossa hipótese e os resultados de Mendes (2013) e coloca em dúvida a forma de correção de redações utilizada atualmente, como um instrumento avaliador isento e justo.

O artigo está organizado da seguinte forma: a próxima seção apresenta os procedimentos metodológicos da pesquisa; a Seção 3 traz a construção da lista de operadores de viés; a Seção 4 apresenta os resultados e análises e a Seção 5 inclui uma breve apreciação da possível extensão desses resultados para as correções de redação do ENEM. A Seção 6 apresenta as considerações finais do trabalho.

\section{Metodologia}

\subsection{Metodologia linguística}

Tomamos como objeto principal de investigação os textos de correção de redação publicados no banco de redações do UOL. Esse banco é um serviço online que tem como objetivo estimular estudantes a treinar produção de textos do tipo argumentativo. Professores associados ao banco corrigem os textos enviados, que são publicados mensalmente no site, juntamente com as respectivas correções. As avaliações são baseadas nos critérios adotados para a correção da redação do ENEM, que são os seguintes: domínio da norma culta do português, compreensão e desenvolvimento do tema baseados em conhecimentos gerais, capacidade de argumentação, conhecimento de mecanismos linguísticos de coesão e elaboração de uma proposta de intervenção, respeitando os valores humanos e a diversidade cultural.

Preocupados em manter um maior rigor na quantificação dos dados, compilamos um corpus de correções composto de 610.543 palavras. Para chegar a esse valor, seguimos as afirmações de Aluísio \& de Barcellos Almeida (2006) e Sardinha (2002). Conforme Aluísio \& de Barcellos Almeida (2006), para estudos de processos gramaticais, é necessário um corpus de 500 mil a 1 milhão de palavras. Conforme Sardinha (2002), um corpus médio para trabalhos na Linguística de Corpus é composto de 500 mil palavras.

Como já mencionamos, além desse corpus, utilizamos dois outros corpora: de resumos acadêmicos e de resenhas. Tivemos o cuidado de comparar textos do mesmo tipo textual da correção de redação, o argumentativo stricto sensu. Conforme Marcuschi (2002), os tipos textuais podem ser classificados em categorias 
como a narração, a exposição, a descrição, a injunção (ou prescrição) e a argumentação stricto sensu. Esses tipos são definidos por estruturas linguísticas. $\mathrm{O}$ tipo argumentativo stricto sensu se caracteriza pela sequência de relações entre argumentos e conclusões, sendo marcado pela presença de "operadores argumentativos". Todos os textos analisados aqui se caracterizam por apresentarem esse esquema básico de estrutura linguística, em que argumentos levam a uma conclusão e são marcados pela presença de operadores argumentativos, que podem ser vistos nos exemplos de correção (1), de resumo (2) e de resenha (3):

(1) Na realidade, o texto não argumenta a respeito de aspectos positivos ou negativos da questão, mas apenas arrola elementos do senso comum para discorrer sobre o tema. ${ }^{1}$

(2) Além disso, os professores e os alunos estão submetidos a uma alta infraestrutura e alto conhecimento em informática... ${ }^{2}$

(3) E ótima facil de usar tem boa imagem e até na grvação,exelente. (sic) ${ }^{3}$

Esses textos argumentativos, apesar de compartilharem características tipológicas, se distinguem em gênero, por terem funções sociocomunicativas distintas. O gênero correção de redação tem como função apontar problemas de uma redação, de acordo com uma lista de critérios. Sua finalidade é justificar a nota atribuída à redação. Já o resumo acadêmico se caracteriza pela função de levar o alocutário a compreender o conteúdo de um texto base, sem ter tido acesso a ele. O resumo deve ser sucinto e fiel ao conteúdo do texto original. Resumos acadêmicos obedecem a rígidas regras de formulação, que incluem restrições sobre formatação, tamanho e conteúdo (Motta-Roth \& Hendges, 2010; Japiassú, 2013). E a resenha é um gênero que compreende textos em que o locutor decididamente explicita sua opinião sobre algo. Sua função é avaliar um determinado objeto, com base em experiências prévias, e recomendá-lo ou não ao alocutário. Assim, apesar de serem do mesmo tipo, por possuírem funções sociocomunicativas diferentes, esses gêneros também possuem diferentes marcas de subjetividade. Além dos operadores argumentativos, outros tipos de operado-

\footnotetext{
${ }^{1}$ https://educacao.uol.com.br/bancoderedacoes/ redacao/ult4657u82.jhtm. Acesso: 27/08/2019.

${ }^{2}$ Damasceno et al. (2016)

${ }^{3}$ https://sites.google.com/icmc.usp.br/ opinando/. Acesso: 05/12/2019.
}

res linguísticos também contribuem para a argumentação, tornando os textos mais ou menos subjetivos.

Tendo isso como premissa, e também tendo como norte parâmetros de uniformidade entre os três corpora, no que diz respeito ao tamanho de cada texto e ao número total de palavras, foram feitas buscas na internet para compor os grupos de comparação. O corpus de resumos acadêmicos foi construído através de consultas e extrações automáticas do Google Scholar ${ }^{4}$. As áreas de pesquisa selecionadas foram as mais variadas, desde Ciências da Computação até Artes e Educação Física. Adotamos essa diversidade para mantermos um equilíbrio entre o caráter mais ou menos subjetivo da linguagem adotada nas diversas áreas do conhecimento. O número de palavras total desse corpus é 460.011. E coletamos também textos do gênero resenha, extraídos do corpus já compilado "Buscapé" (Hartmann et al., 2014) sobre os mais variados temas, desde câmeras fotográficas, passando por balança e até apontador. Esses textos são comentários feitos por consumidores sobre produtos em sites de vendas na internet. Esse corpus possui 717.096 palavras.

Após a compilação dos corpora, elaboramos, manualmente, a lista de operadores de viés linguístico para ser aplicada automaticamente aos três grupos analisados. Para elaborarmos essa lista, nos valemos da metodologia de análise de "detecção de linguagem enviesada" (Recasens et al., 2013), previamente utilizada para o inglês. Uma primeira ideia foi que poderíamos usar a tradução dessas palavras já analisadas em inglês para a nossa análise de textos no português. Entretanto, como é assumido na área de Semântica Lexical (Levin \& Rappaport Hovav, 1995), a tradução de palavras de uma língua para outra não é algo trivial; sempre existem nuances de sentido e muita interferência de contexto sentencial. Com isso, optamos por nos pautar somente na metodologia de desenvolvimento da lista das palavras indutoras de viés e elaborar uma lista específica para o português.

Recasens et al. (2013) propõem analisar exemplos reais de edição de textos da Wikipedia para remover os vieses linguísticos de artigos, que deveriam ser textos isentos de opinião. A ideia é que a partir do entendimento da realização desses vieses, feita por falantes nativos do inglês, podese propor um detector de viés automático composto de palavras indutoras de vieses linguísticos. Os autores mostram que o modelo de informação linguística de viés desenvolvido teve uma per-

\footnotetext{
${ }^{4}$ https://scholar.google.com/

${ }^{5}$ https://sites .google.com/icmc .usp.br/opinando
} 
formance muito próxima da análise de linguagem enviesada feita pelos falantes nativos. Recasens et al. (2013) se valem de trabalhos propostos na literatura que abordam o viés linguístico associado a pistas lexicais e gramaticais sobre subjetividade (Wiebe et al., 2004), sobre sentimento (Liu et al., 2005; Lin et al., 2011; Turney, 2002) e, especialmente, sobre atitudes (Lin et al., 2006; Somasundaran \& Wiebe, 2010; Yano et al., 2010; Conrad et al., 2012). Os autores dividem os tipos de vieses em dois grandes grupos: os vieses epistemológicos e os vieses estruturais. Os vieses epistemológicos podem ser detectados pela presença de verbos factivos (Kiparsky \& Kiparsky, 1968), verbos implicativos (Karttunen, 1971), verbos assertivos (Hooper, 1974) e operadores de modalização 'hedges' (Yule, 1996); os vieses estruturais podem ser detectados por intensificadores subjetivos e termos tendenciosos (Lin et al., 2006).

Ao iniciarmos a análise dos nossos textos, porém, percebemos que os dois grandes grupos propostos pelos autores não captavam uma questão fundamental para a compreensão e detecção dos vieses de forma automática, que seria o problema do sentido dependente de contexto. Dividimos, então, as palavras e expressões que comporiam a nossa lista em dois grandes grupos distintos dos propostos por Recasens et al. (2013): expressões carregadas de sentido que variavam a significação segundo o contexto, ou seja, expressões dependentes de contexto (geralmente, as classes gramaticais abertas, como nomes, verbos e adjetivos) e expressões cujos significados não dependem de contexto, consideradas mais "leves" semanticamente (geralmente, as classes gramaticais fechadas, como advérbios, preposições e conjunções). Pode-se associar os tipos de vieses propostos por Recasens et al. (2013) a esses dois grupos da seguinte forma: expressões dependentes de contexto são os termos tendenciosos, os verbos implicativos e os verbos assertivos; expressões não-dependentes de contexto são os operadores de modalização, os verbos factivos e os intensificadores subjetivos.

Com esses pressupostos teóricos e a nossa intuição de falantes do português, partimos para o trabalho minucioso da análise dos textos coletados. Fizemos primeiramente a análise de 50 correções, aleatoriamente selecionadas, apontando, segundo os critérios linguísticos acima, todas as palavras e expressões que nos pareciam indicar algum tipo de subjetividade do corretor.

Entretanto, ao examinarmos expressões dependentes de contexto, deparamo-nos com outro problema. Por exemplo, detectamos a seguinte sentença no nosso corpus de correções de redação: a frase final está abstrata demais ${ }^{6}$. A palavra abstrata seria um operador de viés. $\mathrm{O}$ que se espera de um corretor de redação são avaliações sobre a coesão, domínio da norma culta etc. e não a sua opinião sobre "o que é ser abstrato". Portanto, para se detectar um viés linguístico em correções de redação, essa é uma palavra adequada. Por outro lado, se pensamos em um resumo acadêmico na área de Artes, em que o autor descreve uma pintura abstrata, certamente não teremos viés nessa palavra. Como essa, percebemos outras tantas expressões que se comportavam de acordo com o tipo de conteúdo do texto.

Considerando o nosso objetivo de estabelecer uma lista de operadores de viés linguístico que gere um modelo de detecção de viés para qualquer tipo de texto, na nossa proposta, precisamos que essa lista detecte as palavras e expressões enviesadas de correções de redação, de resumos acadêmicos e de textos opinativos de forma indistinta. A partir daí, pretendemos que essa lista seja suficientemente abrangente para a utilização em modelos computacionais para qualquer gênero textual. Contudo, estabelecer os vários contextos para que o significado de expressões com sentidos dependentes de contexto seja detectado em um modelo computacional não é uma tarefa trivial. Percebemos mesmo que a lista de expressões que estávamos gerando apresentava, ela própria, uma natureza enviesada, baseada na nossa intuição de falantes. Em vista desses resultados preliminares, optamos por seguir um caminho distinto do seguido em Recasens et al. (2013) e resolvemos descartar as expressões dependentes de contexto e criar uma lista somente com palavras não-dependentes de contexto.

Isso não significa, porém, que elementos de viés dependentes de contexto não serão também detectados nesse tipo de lista. É importante realçar que essas palavras e expressões funcionam como operadores sobre outros itens lexicais, apontando assim para uma porção maior do grau de subjetividade do texto. Fazendo uma analogia, grosso modo, com a Matemática, as palavras não-dependentes de contexto funcionam como os operadores da adição, subtração, multiplicação etc., que apontam para a relação pretendida entre os números, gerando um produto final. Operadores linguísticos funcionam da mesma forma: estabelecem uma relação entre parcelas do texto, gerando uma interpretação subjetiva como produto. Assim, detectar operadores de viés não-

\footnotetext{
${ }^{6}$ https://educacao.uol.com.br/bancoderedacoes/ redacao/ilusao.jhtm. Acesso: 06/09/2019.
} 
dependentes de contexto em um determinado texto, mesmo que em pouca quantidade, indicará também a presença de viés em outras partes de texto, sobre as quais esses operadores têm escopo.

Dessa forma, voltamos nossa atenção para as palavras e expressões não-dependentes de contexto, que apresentam o mesmo tipo de significação em qualquer situação. À primeira vista, essas palavras e expressões parecem apresentar menos conteúdo semântico, tendo uma função essencialmente gramatical. Entretanto, para os estudiosos da Semântica Argumentativa, essas expressões são alvo de muita atenção e pesquisa. O que se assume nessa linha teórica é que essas palavras ou expressões "despretensiosas" são as responsáveis por grande parte da força argumentativa dos textos, ou seja, a direção ou sentido para o qual apontam. Segundo Anscombre \& Ducrot (1976); Ducrot (1987), toda língua possui em sua gramática mecanismos que captam essa subjetividade através de marcas linguísticas da argumentação; entre essas marcas, encontram-se as palavras e expressões que denominamos "nãodependentes de contexto".

Com esse procedimento, elaboramos uma lista de 578 itens. Baseados na classificação encontrada em Koch $(2011,2015)$, dividimos esses operadores em quatro tipos: operadores argumentativos, operadores de pressuposição, operadores de modalidade e operadores de opinião e valoração ${ }^{7}$.

A partir desse trabalho metodológico, a lista construída foi aplicada a cada um dos corpora mencionados acima e os operadores de viés de cada texto foram quantificados e comparados. A seguir, indicamos com mais detalhes como foram feitas as compilações dos corpora e como fizemos a quantificação dos operadores de viés nas correções de redação e a comparação com os demais gêneros analisados.

\subsection{Metodologia computacional}

A compilação dos corpora utilizados nesta pesquisa foi feita de forma automática, a partir de buscas em bancos de textos dos gêneros analisados. Nosso corpus principal se compõe de textos do gênero correção de redação. Esse corpus foi construído a partir da extração automática de textos do banco de redações do UOL, considerando-se um período de cerca de 10 anos. Relembrando, o número total de palavras é de 610.543 .

\footnotetext{
${ }^{7}$ Esse léxico de operadores de viés está disponível em https://bit.1y/2sJzt21
}

Adicionalmente, construímos dois outros corpora para comparação: um de resumos acadêmicos, com 460.011 palavras e outro de resenhas, com 717.096 palavras $^{8}$. Para a composição do corpus de resumos, os textos foram extraídos de consultas automáticas ao Google Scholar, considerando-se diversas áreas do conhecimento, retiradas do site da Universidade Federal de Minas Gerais. Para se determinar os tipos de consulta, lançamos mão do repositório de teses e dissertações dessa universidade ${ }^{9}$, selecionando as palavras-chave em teses ou dissertações. Usamos um programa que fazia consultas e downloads de artigos no Google Scholar e foram extraídos os resumos desses textos. Se a quantidade de palavras era pequena (menos de 50) ou muito grande (mais de 1000), os textos eram descartados. Foi feita uma verificação manual de alguns desses textos e constatamos que a metodologia de extração de dados era confiável.

O corpus de resenhas consiste num fragmento, também extraído de forma automática, do Corpus Buscapé. A utilização de apenas um fragmento do Corpus Buscapé foi necessária para manter a uniformidade com os demais corpora, tanto no número total de palavras quanto no tamanho dos textos. Utilizamos apenas as resenhas do Corpus Buscapé com mais de 200 palavras, pois muitas delas eram curtas e não serviam à nossa comparação, e tentamos manter um número próximo ao total de palavras dos demais corpora.

No processamento computacional que realizamos desses dados, cada texto, seja uma correção de redação, uma resenha ou um resumo, foi considerado um "documento", representado por $d$. Cada documento foi processado a fim de se computar a proporção de ocorrências de operadores de viés, em relação ao número total de palavras do texto. A metodologia utilizada para fazer esse cálculo seguiu os seguintes passos:

\section{Divisão dos documentos em tokens.}

Dividimos os documentos em unidades linguísticas menores: as palavras e expressões fixas comparáveis a palavras, que chamamos de tokens. Os documentos foram, assim, tokenizados e essas unidades, ou tokens, foram identificadas a partir de sua separação gráfica

\footnotetext{
${ }^{8}$ Apesar de haver uma diferença no número de palavras total dos corpora (de $25 \%$ entre os resumos e as correções e de $35 \%$ entre as resenhas e as correções), os cálculos da frequência de ocorrência dos operadores de viés em cada corpus foram feitos proporcionalmente. Assim, essa diferença não teve impacto em nossos resultados.

${ }^{9}$ https://repositorio.ufmg.br/custom/ presentation.jsp
} 
por símbolos, como espaço e hífen. Utilizamos para esse fim a função word_tokenize, da biblioteca de código NLTK $^{10}$. Essa biblioteca possui diversas funcionalidades prontas para uso em processamento de linguagem natural. A partir desse processo, é possível identificar e quantificar operadores de viés em um texto, já que ocorrências desses operadores fazem parte do conjunto de tokens de um documento.

2. Classificação de partes do discurso.

O próximo passo da nossa metodologia foi determinar a categoria gramatical dos tokens, em termos de classes de palavras. Para isso, utilizamos um classificador de partes do discurso, o POS Tagging, também da biblioteca NLTK. Para construir o modelo do classificador de partes do discurso, a base de dados utilizada foi o Mac Morpho (Aluísio et al., 2003) e o código para sua construção pode ser facilmente reproduzido.

3. Lematização de operadores verbais.

Categorizar os tokens nos documentos analisados foi essencial para esta terceira etapa metodológica, a lematização. Lematização é uma técnica utilizada para buscar palavras, abrangendo um paradigma de opções relacionado a elas. No caso de verbos que se encontram na nossa lista de operadores de viés, é feita a lematização, de forma que seja possível a busca por todo o paradigma de flexões desse item. Um exemplo é o verbo começar, para o qual a utilização do lematizador possibilita a busca por todo o paradigma flexional: comecei, começamos, começando etc. Para palavras invariáveis e expressões fixas, mesmo que sejam verbais, não é feita a lematização. Por exemplo, as expressões desde que ou é bom que não passam pelo lematizador, sendo buscadas sempre na mesma forma fixa. Esse processo permite que sejam identificados, dentre os tokens de um documento, todas as formas possíveis de um operador de viés verbal. Para esta etapa, utilizamos a linguagem de programação Java, pois a biblioteca de código, chamada de LemPORT, é baseada em Java. O processo utilizado por esta biblioteca de lematização está descrito em Rodrigues et al. (2014).

4. Uniformização dos tokens através da utilização de caixa baixa.

A terceira etapa da metodologia computacional consistiu em colocar todos os caracteres dos tokens de cada documento em letras

\footnotetext{
${ }^{10}$ https : //www.nltk.org
}

minúsculas, para que esses tokens se tornem "visíveis" a programas computacionais utilizados no processamento dos documentos.

5. Identificação dos operadores de viés em cada documento.

A fim de contabilizarmos o número de ocorrências dos operadores de viés nos documentos dos corpora, primeiramente, identificamos em cada documento os tokens correspondentes a operadores da nossa lista. Para isso, comparamos os tokens dos documentos de cada corpus com cada operador de viés listado. Sendo o token uma ocorrência de um desses operadores, ele seria, então, computado em um acumulador que chamamos de $i_{c}$. O resultado final desse cálculo $i_{c}$ é, portanto, o número de ocorrências de operadores de viés de um determinado tipo em um documento. Cada documento apresentou, assim, quatro números desse tipo, um para cada tipo de operador de viés.

6. Quantificação de ocorrências de operadores de viés em relação ao número de palavras.

A partir do número de $i_{c}$ foi possível, então, contabilizar o percentual de tokens de um determinado documento que se caracterizavam como operadores de viés. Esse cálculo foi feito da seguinte forma. Para cada documento e para cada tipo de operador de viés, dividimos o acumulador $i_{c}$ pelo número de tokens do documento, representado por $|d|$. Assim, a proporção de ocorrências de operadores de viés, de cada tipo, representada por $P_{c}$, é dada pela fórmula

$$
P_{c}=\frac{i_{c}}{|d|} .
$$

Os passos descritos acima foram implementados na linguagem de programação Python em sua versão $3^{11}$. E com essas etapas metodológicas chegamos ao número de proporção de ocorrências de operadores de viés por documento. Após esse procedimento, analisamos estatisticamente os resultados, a fim de fazer uma comparação entre os três gêneros. Nosso objetivo não foi somente computar os operadores do gênero em análise, as correções, mas observar se esses textos se aproximam mais dos resumos acadêmicos, o polo menos subjetivo, ou das resenhas, o polo mais subjetivo. Para isso usamos uma ferramenta estatística, que será apresentada a seguir.

\footnotetext{
${ }^{11}$ https ://www python.org
} 


\subsubsection{Ferramenta de análise estatística}

Como ferramenta de análise estatística, utilizamos o diagrama de caixa, ou boxplot. O boxplot é uma ferramenta não-paramétrica, auto evidente, e não deixa dúvidas quanto à distribuição empírica dos dados: esse gráfico permite visualizar a distribuição de uma variável em termos da sua locação (mediana/quartis), dispersão (variabilidade), grau de assimetria, presença de valores extremos/discrepantes (outliers), entre outros. Para gerar os boxplot, utilizamos a linguagem $\mathrm{R}^{12}$. A Figura 1 mostra um boxplot padrão, que está marcado com seus principais elementos.

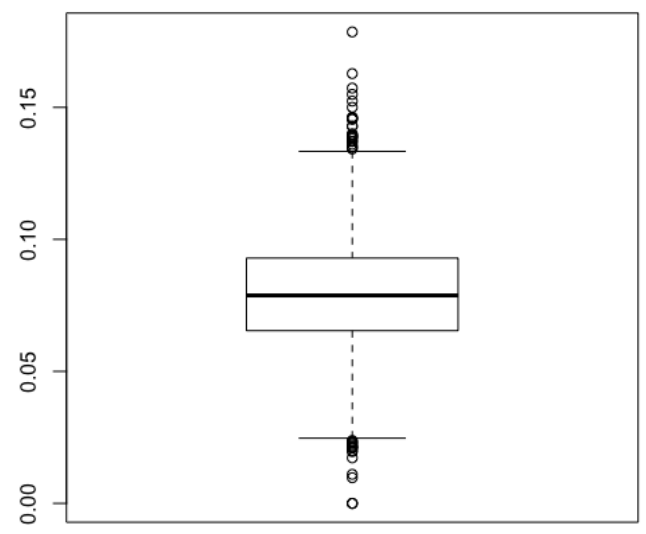

Figura 1: Exemplo de boxplot

Essa figura contém uma "caixa", o retângulo central da figura, com uma linha horizontal mais grossa, duas linhas horizontais menores, uma linha vertical e pontos acima e abaixo das linhas horizontais menores, que aparecem fora da caixa. Cada um desses elementos gráficos possui um significado estatístico, em relação à variação dos dados observados de uma variável numérica. Assim, o gráfico permite a visualização de valores que dividem um conjunto de dados ordenados em quatro partes iguais, que são chamados de "quartis".

A primeira parte, ou primeiro quartil, é o valor que divide $25 \%$ dos menores valores do conjunto de dados dos $75 \%$ restantes. O primeiro quartil é representado pela linha inferior da caixa (abaixo da caixa estão os $25 \%$ dos dados que possuem menor valor). O segundo quartil, ou a mediana, é o valor que divide os dados ordenados ao meio. A mediana é definida como o valor que está no meio de um conjunto de valores (Lane et al., 2017). Outra forma de pensar a mediana é que metade do conjunto de valores, $50 \%$, será menor que o valor da mediana e a outra metade do conjunto, $50 \%$, será maior. Por esta razão, a mediana também é chamada de percentil 50 .

\footnotetext{
${ }^{12}$ Disponível em https://www.rdocumentation.org/ packages/graphics/versions/3.6.1/topics/boxplot.
}

A linha horizontal mais grossa representa a mediana. O terceiro quartil representa o valor que separa dos demais os $25 \%$ dos dados que possuem o maior valor. No boxplot, o terceiro quartil é graficamente representado pela linha horizontal mais acima na caixa. As linhas horizontais menores, que aparecem fora da caixa, indicam os limites dos dados até 1,5 vezes a distância entre os quartis (distribuição interquartílica). Os pontos acima e abaixo dessas linhas representam valores discrepantes, ou outliers, do conjunto. Esses pontos mostram valores que estão no extremo da distribuição. Por fim, o tamanho da caixa está relacionado com a variabilidade do conjunto de dados. Assim, se a distância entre a mediana e os outliers for maior de um lado do que do outro, os dados possuem uma distribuição assimétrica; caso contrário, simétrica. Na Figura 1, o tamanho da caixa nos dois quartis é similar, portanto, a distribuição dos dados é simétrica.

O boxplot é muito útil para a visualização de diferentes conjuntos de dados com relação a uma variável. Este é o caso deste trabalho, já que temos três conjuntos de dados (três gêneros textuais) e quatro variáveis (quatro tipos de operadores de viés). Portanto, para cada tipo de operador, geramos um boxplot e analisamos os resultados. Na seção seguinte, antes de partirmos para a explicitação desses resultados, explicamos com detalhes cada um desses tipos de operadores.

\section{Léxico de operadores de viés linguístico}

Conforme Anscombre \& Ducrot (1976) e Ducrot (1987) (e trabalhos subsequentes), a argumentação, em um sentido mais amplo, está inscrita na língua, não depende exclusivamente de um tipo textual e pode ser guiada por itens específicos da gramática. Como mostramos na metodologia (2.1), o que nos interessa na nossa análise são exatamente esses itens, que apontam para a direcionalidade da argumentação, deixando à mostra o grau de subjetividade do texto. Portanto, são essas marcas linguísticas, que chamamos de "operadores de viés linguístico", que fazem parte da nossa lista, que pode ser também entendida como um "léxico". Lembramos que nosso foco é em expressões não-dependentes de contexto e que essas expressões são operadores que agem sobre porções maiores de texto, resultando em sentenças com implicações subjetivas.

Seguimos as propostas de Koch (2011, 2015), para quem as marcas de argumentação em um texto podem ser expressas através das seguintes categorias: operadores argumentativos, ope- 
radores de pressuposição, operadores de modalidade, operadores de opinião e valoração, tempos verbais e índices de polifonia. Usamos as quatro primeiras categorias, marcas possíveis de serem utilizadas em um detector automático de viés linguístico. Também ampliamos a lista dada pela autora, usando expressões encontradas em nossos dados. A lista completa é composta por 578 itens, sendo 118 operadores argumentativos, 212 operadores de pressuposição, 93 modalizadores e 155 operadores de opinião e valoração. A seguir explicitamos essas quatro categorias ${ }^{13}$.

\subsection{Operadores argumentativos}

Os operadores argumentativos têm a função de estabelecer uma ligação entre as orações, períodos ou parágrafos, deixando transparecer a intenção do locutor. São as estruturas que caracterizam os textos de tipo argumentativo stricto sensu. Segundo Koch (2011, 2015), esses operadores encontram-se divididos em alguns tipos.

Um primeiro tipo é o dos operadores que assinalam o argumento mais ou menos proeminente de uma escala orientada no sentido de determinada conclusão, os chamados "operadores de escala argumentativa". Operadores como esses mostram que o locutor constrói uma escala de argumentos, sendo o mais forte ou o mais fraco introduzido pelo operador. Por exemplo:

(4) A escolha das palavras é, em geral, confusa e ambígua, comprometendo a compreensão das ideias e até mesmo mantendo num nível superficial a análise que faz do tema. ${ }^{14}$

A sentença em (4), retirada do corpus de correções, mostra que o operador até mesmo indica que há uma escala construída pelo locutor: confusa $\rightarrow$ ambígua $\rightarrow$ superficial, em que o valor alto da escala, e talvez não-esperado, "ser superficial", reflete a opinião de quem usa o operador.

Um segundo tipo de operador argumentativo é o que soma um argumento a favor da afirmação feita anteriormente, de uma forma positiva ou mesmo negativa:

(5) A objetividade, aliás, é o ponto mais alto dessa redação. ${ }^{15}$

\footnotetext{
${ }^{13} \mathrm{O}$ léxico completo com todos os operadores encontrase disponível em https://bit.ly/2sJzt21.

${ }^{14}$ https://educacao.uol.com.br/bancoderedacoes/ redacao/a-importancia-de-biografias-autorizadas . jhtm. Acesso: 06/09/2019.

${ }^{15}$ https : //educacao.uol.com.br/bancoderedacoes/ redacao/educacao-e-mais-forte-que-violencia.jhtm. Acesso: 06/09/2019.
}

Na sentença (5), pode-se perceber que há um desfecho glorioso em relação às propriedades da redação, na perspectiva de quem elabora o enunciado.

Um terceiro tipo de operador argumentativo são os que introduzem a conclusão à qual o locutor quer que seu alocutário chegue, a partir dos argumentos apresentados anteriormente:

(6) Não desenvolve, portanto, uma dissertação argumentativa. $^{16}$

Em (6), portanto indica que o fato de que o aluno não desenvolve uma dissertação argumentativa é uma conclusão, que pode ser tirada a partir de argumentos elencados anteriormente. O operador é utilizado pelo produtor do texto como um "guia" para que o alocutário compartilhe com ele essa mesma posição.

Um quarto tipo de operador introduz argumentos alternativos que marcam uma conclusão oposta à afirmação anterior, indicando a dúvida do locutor:

(7) Seria melhor substituir a expressão "o casal e os amigos" por "amigos" somente ou então por "par". ${ }^{17}$

Um quinto tipo é o que estabelece relações de comparação entre elementos, indicando uma dada conclusão por parte do locutor:

(8) Mal o aluno acaba de falar de uma coisa, ele pula para outra como se continuasse a falar da mesma. ${ }^{18}$

Um sexto tipo é o que estabelece relações de condição entre elementos, indicando uma imposição por parte do locutor:

(9) Isso se chama tautologia, e deve ser evitado; pode-se repetir, desde que avançando nas ideias. ${ }^{19}$

\footnotetext{
${ }^{16}$ https://educacao uol.com.br/bancoderedacoes/ redacao/bandido-bom-e-bandido-recuperado.jhtm? action=print. Acesso: 11/09/2019.

${ }^{17}$ https://educacao.uol.com.br/bancoderedacoes/ redacao/ult4657u564.jhtm. Acesso: 06/09/2019.

${ }^{18} \mathrm{https}$ ://educacao.uol.com.br/bancoderedacoes/ redacoes/policia-e-bandido-violencia-no-seculoxxi.htm. Acesso: 06/09/2019.

${ }^{19}$ https://educacao.uol.com.br/bancoderedacoes/ redacao/ult4657u488.jhtm. Acesso: 06/09/2019.
} 
Um sétimo operador introduz uma justificativa ou explicação do locutor, em relação ao enunciado anterior:

(10) ... desse modo, fica impossível atribuir alguma nota às competências 2,3 e $4 .^{20}$

Um oitavo tipo contrapõe argumentos, indicando conclusões contrárias:

(11) ... a análise das causas é simplificadora e superficial, apesar de plausível $^{21}$

O locutor faz uma afirmação, mas introduz uma contraposição ao seu argumento, criando uma expectativa contrária no alocutário. Esses operadores ligam dois argumentos opostos, mas sempre colocam mais relevância para um dos argumentos, aquele que corrobora a conclusão pretendida.

\subsection{Operadores de pressuposição}

Um segundo grupo de operadores de viés linguístico são expressões que têm a função de introduzir no texto um conteúdo pressuposto, aos quais chama-se na literatura de "desencadeadores de pressuposição". Quando usamos itens linguísticos que trazem em si uma verdade assumida anteriormente, estamos impondo aos alocutários essa verdade, o que nem sempre pode ser um fato, mas pode corresponder à opinião de quem a enuncia, ou seja, o uso de operadores de pressuposição é uma "manobra argumentativa"(Fiorin, 2007).

Um primeiro tipo desses operadores (agora, ainda, atualmente etc.) é exemplificado a seguir, com trechos retirados das próprias correções que compõem o nosso corpus.

(12) Acrescenta-se uma informação já esboçada anteriormente.... $^{22}$ (pressuposto: a informação não devia aparecer novamente)

Além dessas marcas temporais, existem alguns conectores circunstanciais, sobretudo quando a sentença introduzida por eles vem anteposta, que são desencadeadores de pressuposição; toma-se como fato o conteúdo da sentença introduzida pelo conector:

\footnotetext{
${ }^{20}$ https: //educacao.uol.com.br/bancoderedacoes/ redacoes/uma-perda-historica-para-o-pais.htm. Acesso: 06/09/2019.

${ }^{21}$ https://educacao.uol.com.br/bancoderedacoes/ redacao/violencia-comeca-em-casa.jhtm. Acesso: $05 / 09 / 2019$

${ }^{22}$ https : //educacao.uol.com.br/bancoderedacoes/ redacoes/violencia-gera-consequencia.htm. Acesso: 06/09/2019
}

(13) Depois de um caótico e redundante parágrafo introdutório, o autor começa a dizer contrassensos ou a usar conceitos vagos... ${ }^{23}$ (pressuposto: o parágrafo introdutório é caótico e redundante)

Outros exemplos de operadores de pressuposição são expressões verbais que denotam uma mudança ou uma manutenção do estado; essas expressões pressupõem o estado anterior à mudança ou a ocorrência prévia do estado que se mantém; por exemplo:

(14) O que o autor parece não perceber é que o trote vem se tornando mais violento hoje em dia. (pressuposto: o trote antes era menos violento)

Um último tipo de operador de pressuposição são os verbos chamados "factivos". Quando empregados, esses verbos desencadeiam a pressuposição da verdade do seu complemento sentencial. Um exemplo desse tipo de verbo é notar:

(15) Note-se ainda que o texto não justifica o título. $^{24}$

Na sentença acima, toma-se como verdade que "o texto não justifica o título". Quando expressões contendo esses verbos são usadas, há uma indução do alocutário a aceitar uma opinião do locutor como verdade.

\subsection{Operadores de modalidade}

Os operadores de modalidade, ou modalizadores, são elementos lexicais (e gramaticais, que não abordaremos aqui) pelos quais o locutor manifesta uma determinada atitude em relação ao conteúdo de seu próprio enunciado. Pode-se dividir, de uma maneira mais ampla, os modalizadores em dois tipos, segundo Pires de Oliveira (2001): os de possibilidade e os de necessidade. Esses dois tipos de modalizadores podem expressar a possibilidade e a necessidade de acordo com normas morais ou legais, os modalizadores deônticos, ou podem expressar a necessidade e a possibilidade em relação ao conhecimento e à crença do locutor, os modalizadores epistêmicos.

\footnotetext{
${ }^{23}$ https://educacao.uol.com.br/bancoderedacoes/ redacoes/brasil-por-uma-migracao-seguraordenada-e-regular.htm. Acesso: 06/09/2019.

${ }^{24}$ https://educacao.uol.com.br/bancoderedacoes/ redacao/os-desafios-da-interacao.jhtm. Acesso: 06/09/2019
} 
Esses operadores linguísticos podem vir lexicalizados na forma "verbo ser + adjetivo"):

(16) É preciso evitar esse tipo de redundância, resultante da falta de planejamento na criação do texto. ${ }^{25}$ (necessidade)

Os modalizadores também podem aparecer na forma de advérbios ou locuções adverbiais (certamente, sem dúvida, de fato):

(17) Texto fraco, marcado pelo uso inadequado do vocabulário, em que as palavras são usadas com significados que, de fato, não têm. ${ }^{26}$ (necessidade)

Ainda, modalizadores podem ser verbos modais:

(18) É o máximo que se pode extrair de um texto cuja linguagem obscura parece usada para iludir e impressionar o alocutário... ${ }^{27}$ (possibilidade)

A modalização aparece também em orações modalizadoras (tenho a certeza de que, existe a possibilidade de etc.):

(19) Não há necessidade de usar essa locução no trecho assinalado. ${ }^{28}$ (possibilidade)

E, por fim, aparece em certos tipos de verbos que denotam crença ou sentimento (achar, acreditar, desejar etc.):

(20) O autor crê que o leitor deva subentender o que ele está dizendo com essas expressões incorretas, mas não é assim que funciona a comunicação escrita. ${ }^{29}$ (possibilidade)

\subsection{Operadores de opinião e valoração}

Finalmente, apresentamos os operadores de opinião e valoração. Operadores de opinião apontam para um determinado estado psicológico, um certo tipo de sentimento, de opinião que o locutor assume em relação ao conteúdo de seu enunciado.

\footnotetext{
${ }^{25}$ https://noticias.uol.com.br/educacao/ bancoderedacoes/redacao/ult4657u67.jhtm 06/09/2019

${ }^{26}$ https: //educacao.uol.com.br/bancoderedacoes/ redacao/horario-apolitico.jhtm. Acesso: 05/09/2019.

${ }^{27}$ https : //educacao.uol.com.br/bancoderedacoes/ redacoes/menos-influencia-estatal-nao-significamenos-ordem.htm. Acesso: 05/09/2019.

${ }^{28}$ https : //educacao.uol.com.br/bancoderedacoes/ redacao/ult4657u140.jhtm. Acesso: 05/09/2019

${ }^{29}$ https ://educacao.uol.com.br/bancoderedacoes/ redacoes/justica-pra-alguns-stf-pra-outros.jhtm. Acesso: 18/12/2019
}

Podem ser indicadores desse tipo expressões adverbiais, expressões verbais e alguns adjetivos que não têm alteração do sentido segundo o contexto. Veja um exemplo:

(21) Além disso, em vermelho, é ruim usar duas vezes seguidas o "porém, atualmente" 30

Ainda, dentro dessa categoria, podem-se incluir os operadores de valoração. Segundo Koch (2015), a atitude subjetiva do locutor pode ser medida também pela avaliação e valoração dos fatos, estados ou qualidades atribuídas a um referente. Em geral, essa medição se dá por expressões adjetivas e intensificadores. Veja um exemplo de valoração extraído das correções:

(22) A sugestão que conclui a redação também é retórica e panfletária, propondo manifestações contrárias ao que está aí, que foi analizado (sic) de modo excessivamente genérico... ${ }^{31}$

Apresentamos, em seguida, os resultados da análise do viés linguístico nas correções, feita a partir da aplicação automática do léxico dos operadores de viés. Apresentamos também o resultado comparativo da aplicação dessa lista nos textos dos nossos outros dois corpora, o de resumos acadêmicos e o de resenhas.

\section{Resultados e análise dos dados}

Antes de procedermos à análise, é importante observar que os números de porcentagens obtidos podem não ser expressivos numericamente, mas indicam com clareza como se dá a distribuição dos operadores nos três corpora comparados. Como já observado, o número de operadores em relação ao número de outras categorias linguísticas que compõem um texto é muito pequeno, assim como são poucos os operadores matemáticos em relação aos números. Então, é de se esperar que a porcentagem dessas ocorrências nos textos analisados seja um número baixo. Mas, como mostramos na Seção 3, esses operadores agem sobre expressões linguísticas e até mesmo sobre sentenças inteiras, resultando em porções maiores de texto com implicações subjetivas. Analisando dessa forma, o grau de subjetividade não se encontra somente no número absoluto de operadores, mas, sim, em todo o produto

\footnotetext{
${ }^{30}$ https://noticias.uol.com.br/educacao/ bancoderedacoes/redacao/ult4657u27.jhtm. Acesso: 05/09/2019.

${ }^{31}$ https : //educacao.uol.com.br/bancoderedacoes/ redacoes/educacao-brasileira-conhecimento-ja.htm. Acesso: 05/09/2019.
} 
final da interpretação daquela porção linguística gerada pelo operador. Por isso, para uma análise automática, assumimos que a presença dos operadores nos textos nos dá evidências quantitativas de que uma porção maior do texto apresenta um grau de viés linguístico.

Para iniciar a análise, apresentamos, na Tabela 1, o número absoluto de ocorrências de cada tipo de operador de viés em cada corpus analisado.

\begin{tabular}{cccc}
\hline Tipo de & \multicolumn{3}{c}{ Gênero } \\
\cline { 2 - 4 } operador de viés & Correção & Resenha & Resumo \\
\hline Argumentativo & 48912 & 39282 & 18949 \\
Opinião/valoração & 12742 & 22604 & 3903 \\
Pressuposição & 6081 & 10750 & 947 \\
Modalidade & 5446 & 4539 & 1074 \\
\hline
\end{tabular}

Tabela 1: Ocorrências de operadores de viés por gênero

Os números da Tabela 1 mostram que os operadores argumentativos e de opinião e valoração ocorrem em maior quantidade que os demais operadores, nos três gêneros analisados. Ainda, as correções apresentam números mais próximos da resenha que do resumo.

Porém, uma análise por valores absolutos não é suficiente para mostrar e comparar como essas ocorrências são distribuídas pelos textos específicos que compõem cada corpus. Por isso, analisamos os números de ocorrências de cada tipo de operador distribuídos por cada texto de cada gênero, o que nos dá a proporção desses operadores em relação ao número de tokens de cada documento, a partir da fórmula $P_{c}=\frac{i_{c}}{|d|}$, como explicitado na metodologia. Partindo-se, então, dessa proporção, foram gerados boxplots, a fim de facilitar a visualização dessa distribuição. Os diagramas das Figuras 2, 3, 4 e 5, ilustrativos para cada tipo de operador de viés, são mostrados a seguir.

Primeiramente, temos o diagrama que mostra o comportamento dos operadores argumentativos nos três gêneros analisados na Figura 2.

Na Figura 2, a linha no meio dos retângulos aponta para a mediana das ocorrências por corpus. Comparando os três grupos, a mediana nas correções de redação é de 0,08 , nas resenhas é de 0,05 e nos resumos é de 0,04. Esses números indicam que a porcentagem de ocorrência desses operadores nas correções é maior do que nas resenhas e nos resumos, o que pode ser verificado visualmente no diagrama. Essa constatação também pode ser evidenciada pelos dados da Tabela 1, que apresenta o valor absoluto das

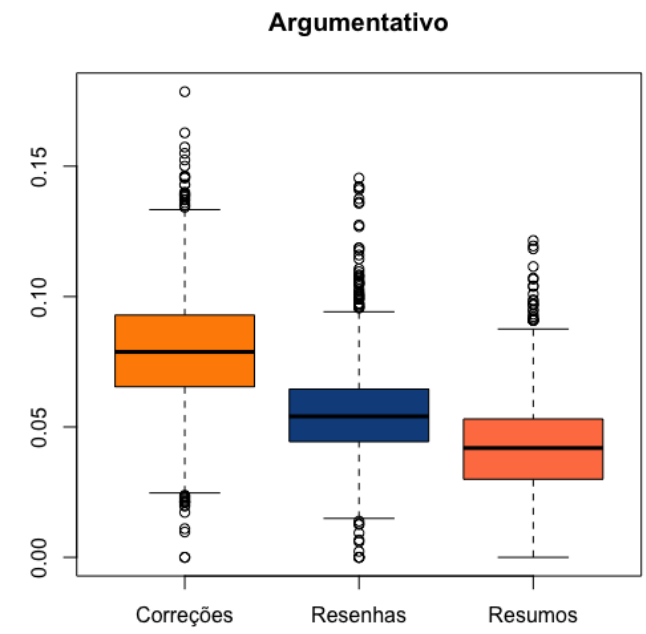

Figura 2: Boxplot para operadores argumentativos

ocorrências dos operadores argumentativos nos três gêneros. As correções também apresentam o maior número desses operadores em valor absoluto.

Outra observação a respeito dos dados da Tabela 1 é que os operadores argumentativos ocorrem em um número bem maior do que os outros operadores. Isso se deve ao fato de serem os três gêneros do tipo textual argumentativo e, por isso, apresentam mais operadores desse tipo. Esse é um resultado esperado. Entretanto, a diferença grande entre as medianas e a diferença numérica entre os gêneros é um resultado inesperado: sendo esses textos do mesmo tipo, argumentativo, era de se esperar uma distribuição e quantidade de operadores mais equilibrada entre eles. Como operadores argumentativos são marcas de subjetividade, isso nos leva a uma primeira análise de que, em relação a essas marcas, o gênero correção de redação já apresenta um maior grau de viés linguístico, na comparação dos três gêneros.

Os pontos de discrepância, ou seja, os outliers, que representam $1 \%$ da população para cima ou $1 \%$ da população para baixo, também estão presentes nos três gêneros, mas isso indica apenas que alguns textos contêm pouquíssimos operadores ou muito mais operadores do que os $50 \%$ distribuídos dentro do retângulo, não trazendo significação para a análise de subjetividade.

O segundo diagrama a ser apresentado é o dos operadores de opinião e valoração que está na Figura 3.

No diagrama da Figura 3, as medianas dividem a distribuição dos operadores de opinião e valoração de forma assimétrica nos três gêneros. A mediana nas correções de redação é de 0,02 , 


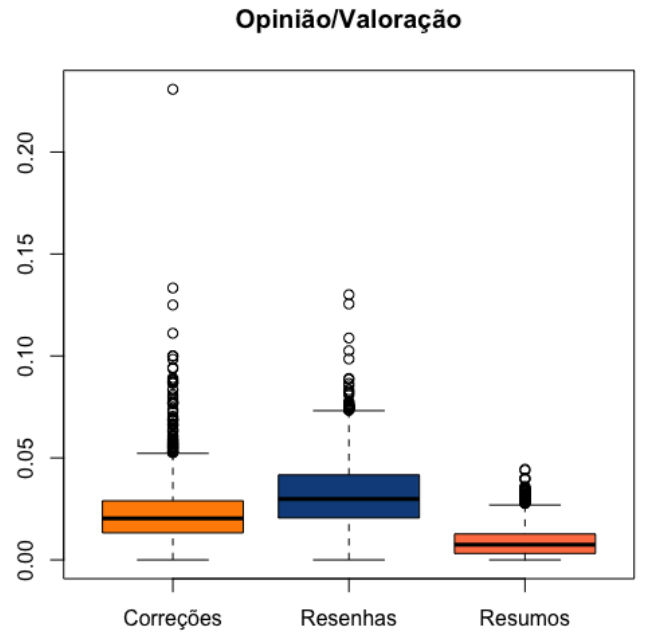

Figura 3: Boxplot para operadores de opinião e valoração

nas resenhas é de 0,03 e nos resumos é muito próxima de 0 . Esses números indicam que a proporção desses operadores nas resenhas é maior do que nas correções e nos resumos, o que pode ser verificado visualmente no diagrama. Esse é um resultado esperado, já que resenhas certamente vão apresentar mais palavras que expressem opinião, visto que a função do gênero é precisamente avaliar. Resumos já apresentam um grau baixíssimo de operadores de opinião e valoração, já que sua função é relatar resultados de uma pesquisa acadêmica da forma menos subjetiva possível. Porém, pensando nas correções e em sua função de ser um instrumento avaliativo isento, o número de ocorrências dos operadores de opinião e valoração deveria estar mais próximo dos resumos, não das resenhas. E, como podemos observar, não é isso que ocorre, já que as correções se aproximam mais da resenha do que do resumo acadêmico, em relação a esses marcadores e, consequentemente, ao grau de subjetividade. Essa é mais uma evidência em direção à nossa hipótese inicial, de que as correções são mais subjetivas do que se esperaria.

Também os dados da Tabela 1 evidenciam que, em termos de valor absoluto das ocorrências dos operadores de opinião e valoração, as correções se aproximam mais das resenhas do que dos resumos. É uma grande diferença em termos numéricos: as resenhas apresentam 22.604 ocorrências desses operadores, as correções 12.742 e os resumos apenas 3.903.

Os outliers do diagrama da Figura 3 ainda nos dão um outro tipo de evidência: quando existe algum desvio nas correções, esses desvios são somente para cima, ou seja, documentos que se desviam do comportamento da maioria apresentam sempre um número maior de operadores de opinião e valoração e chegam mesmo a ultrapassar os desvios dos textos de resenhas, em amplitude e em quantidade. Não seria de se esperar que pudessem aparecer no corpus correções com um grau de viés maior do que o das resenhas.

Passemos, agora, para os diagramas com os operadores de pressuposição e de modalidade, que estão respectivamente nas Figuras 4 e 5.

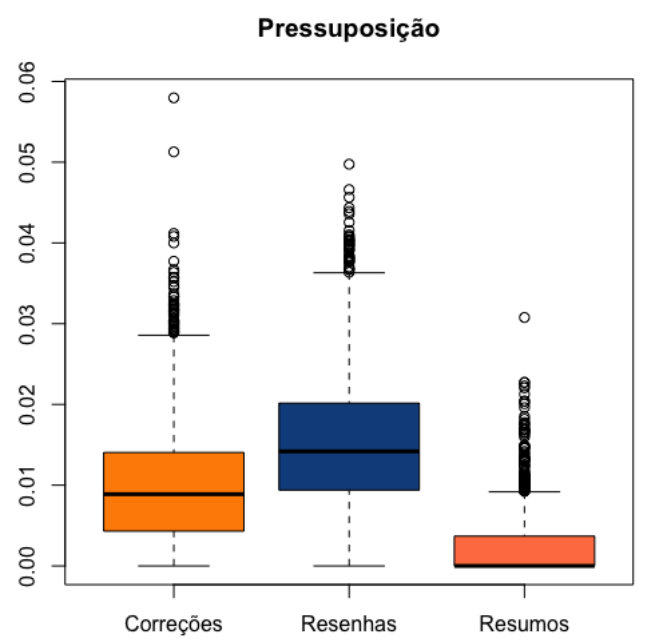

Figura 4: Boxplot para operadores de pressuposição

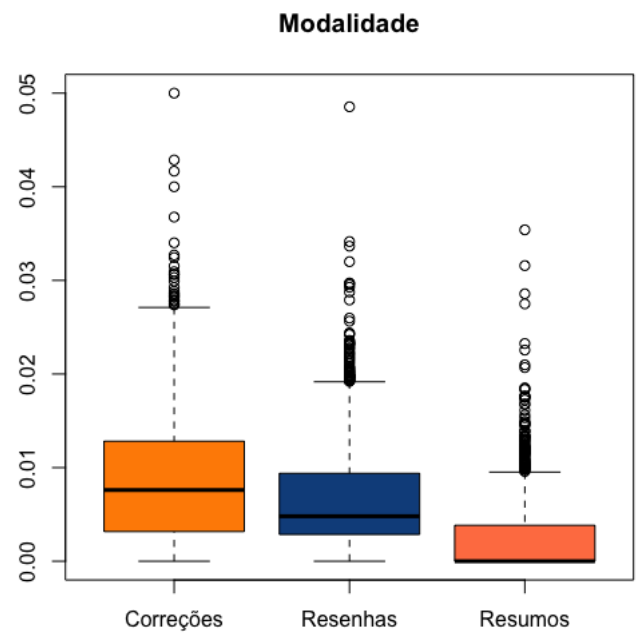

Figura 5: Boxplot para operadores de Modalidade

Esses dois tipos de operadores apresentam uma menor relevância no grau do viés, pois, como pode ser visto nos diagramas, as medianas dos três gêneros não ultrapassam 0,01. Entretanto, ainda assim, é possível notar visualmente nos boxplots que a mediana das correções, tanto na pressuposição como na modalidade, se aproxima mais das resenhas. E, no número dos operadores de modalidade, as correções chegam a ultrapassar as resenhas. Mostramos na Tabela 2 as medianas desses dois operadores. 


\begin{tabular}{cccc}
\hline Tipo de & \multicolumn{3}{c}{ Gênero } \\
\cline { 2 - 4 } operador de viés & Correção & Resenha & Resumo \\
\hline Pressuposição & 0,009 & 0,014 & 0 \\
Modalidade & 0,008 & 0,005 & 0 \\
\hline
\end{tabular}

Tabela 2: Medianas para operadores de pressuposição e modalidade

Em relação aos outliers, um fato interessante a se notar é que os desvios ocorrem sempre em uma direção maior de viés e em uma maior amplitude nas correções, assim como ocorre para os operadores de opinião e valoração.

Também nos valores da Tabela 1 as correções se aproximam mais das resenhas do que dos resumos, apresentando um valor maior para os modalizadores. O que se pode concluir desse padrão é que também no comportamento desses dois operadores, ainda que em menor relevância, as correções se aproximam mais das resenhas, inclusive ultrapassando-as na categoria de modalidade. Esse comportamento não seria esperado, dada a função do gênero correção de redação. Esses resultados corroboram, novamente, a hipótese levantada.

Como última evidência para a nossa hipótese, fizemos uma comparação em termos de percentual de operadores por tipo de gênero, tomando cada corpus como um único extrato do gênero e como sendo uma população homogênea. Obtivemos o resultado descrito na Tabela 3 .

\begin{tabular}{cccc}
\hline Tipo de & \multicolumn{3}{c}{ Gênero } \\
\cline { 2 - 4 } operador de viés & Correção & Resenha & Resumo \\
\hline Argumentativo & 0.080 & 0.055 & 0.041 \\
Opinião/valoração & 0.020 & 0.032 & 0.008 \\
Pressuposição & 0.010 & 0.015 & 0.002 \\
Modalidade & 0.009 & 0.006 & 0.002 \\
\hline
\end{tabular}

Tabela 3: Percentual dos operadores por gênero

Os dados da Tabela 3 corroboram todas as análises anteriores, feitas para a distribuição desses operadores por documentos de cada gênero. Primeiramente, pode-se notar que o percentual de ocorrências de operadores argumentativos, nos três gêneros, também é maior do que dos outros operadores. Entre os gêneros, as correções apresentam o maior número dessas marcas, indicando o maior grau de viés. Em relação aos operadores de opinião e valoração, também temos um maior número de ocorrências para o gênero resenha, o esperado para um gênero avaliativo e opinativo. O número de ocorrências para as correções também é alto e se aproxima muito mais das resenhas, o que não é esperado para um texto que deveria ter um caráter menos subjetivo. Finalmente, como nos boxplots, a pressuposição e a modalidade apresentam um número menos relevante para o diagnóstico de viés nos três gêneros. Mas, mesmo assim, a correção também se aproxima mais das resenhas do que dos resumos e, ainda, apresenta valores que chegam a superar aqueles encontrados para as resenhas.

Com a Tabela 3, que mostra os percentuais de ocorrência dos tipos de marcadores no conjunto de cada corpus, tomado como uma unidade, evidenciamos que as características de subjetividade encontradas para as correções pertencem ao gênero, e não provêm de peculiaridades individuais de corretores. As análises por documento e a análise geral do corpus levam à mesma conclusão e nossos resultados indicam uma uniformidade de comportamento desses textos, enquanto parte de um mesmo gênero textual.

Concluindo a análise, os resultados apresentados nos levam a confirmar nossa hipótese: as correções de redação apresentam um maior grau de viés linguístico do que o esperado para esse gênero textual. Em termos de distribuição de operadores de viés, as correções se aproximam mais de resenhas (o polo mais subjetivo) do que de resumos acadêmicos (o polo menos subjetivo), até mesmo superando as resenhas para alguns tipos de operadores.

\section{Uma breve reflexão sobre a correção das redações do ENEM}

Com a análise apresentada aqui, vimos que os textos de correção de redação se assemelham a resenhas. Isso evidenciou o caráter mais subjetivo, não esperado, para o gênero. Tal resultado coloca em dúvida também a isenção do processo de correção das redações do ENEM. Como as correções de redação do nosso corpus, retiradas do banco do UOL, se assemelham muito às correções das redações do ENEM, tanto nos critérios adotados, quanto no perfil dos corretores, o resultado encontrado nesta pesquisa é uma evidência do possível grau de viés linguístico existente também na correção de redações feitas nesse exame. Entendemos que, para confirmarmos tal hipótese, o ideal seria termos acesso aos textos das próprias correções de redações do ENEM. Contudo, essa avaliação é feita por uma grade de cinco competências, já estabelecidas pelos elaboradores da prova, em que o corretor deve apontar uma nota específica de 0 a 200 para cada habilidade. Assim, o processo individual de como cada corretor chegou a uma determinada pontuação fica oculto. 
Acrescentamos ao nosso resultado, ainda, três outras evidências do alto nível de subjetividade das correções de redação do ENEM, já apontadas de forma detalhada em Mendes (2013). A primeira evidência diz respeito ao processo, propriamente, de correção das redações. As redações do ENEM são submetidas a dois avaliadores distintos, que não se comunicam. Eles corrigem pelo computador em torno de 50 a 70 redações por dia. O avaliador é remunerado por produtividade; quanto mais redações corrigir, maior será a remuneração. Um novo pacote de textos só é enviado ao corretor quando ele já tiver concluído o anterior. Nota-se nesse processo uma clara sobrecarga dos avaliadores. Nesse ponto, vale a afirmação feita em Mendes (2013) (p. 450) a respeito da interferência do cansaço na atribuição de notas na correção: "Segundo Wolcott \& Legg (1998), em situação de cansaço, a atenção do avaliador começa a fugir, levando-o a sobrepontuar ou penalizar um texto. A tendência, nesse caso, é sacrificar a precisão pela rapidez."

Outro aspecto a se notar é a disparidade das avaliações. Cada avaliador atribui uma nota entre 0 e 200 pontos para cada uma das cinco competências, e a soma desses pontos compõe a nota final de cada avaliador, que pode chegar a 1.000 pontos. As notas atribuídas por esses avaliadores são somadas e é feita a média aritmética. Quando há uma divergência (mais de 100 pontos de diferença entre os dois corretores ou diferença superior a 80 pontos em qualquer uma das competências), essa redação é submetida a uma terceira correção independente. A nota final será a média aritmética das duas notas totais que mais se aproximarem. E, ainda havendo divergência, essa redação é submetida a uma quarta correção, feita por uma banca presencial composta por três professores, que atribuirá a nota final do candidato $^{32}$. Segundo dados do Inep ${ }^{33}$, o número de divergência entre notas atribuídas por diferentes corretores é bastante alto. Temos o seguinte quadro de correções feitas nos anos de 2014, 2015 e 2016, descrito pela Tabela 4 .

A partir desses dados, vemos que uma terceira correção é feita em metade das redações e, ainda, em torno de 200.000 redações são submetidas a uma quarta correção. Esses números corroboram a nossa hipótese de que também no ENEM a correção é altamente subjetiva, já que não há uniformidade nas notas atribuídas em muitos casos.

\footnotetext{
${ }^{32}$ Ver como se dá esse processo em: http: //download.inep.gov.br/educacao_basica/enem/ guia_participante/2017/manual_de_redacao_do_enem_ 2017.pdf.

${ }^{33}$ Fonte: Pedido de informação SIC - Inep $\mathrm{n}^{\circ}$ 23480.004970/2017-81
}

\begin{tabular}{cccc}
\hline & 2014 & 2015 & 2016 \\
\hline Redações corrigidas & 4.338 .259 & 5.598 .545 & 5.637 .484 \\
Submetidas a 3 ${ }^{\mathrm{a}}$ correção & 2.823 .128 & 2.160 .115 & 2.162 .044 \\
Submetidas a 4 $4^{\mathrm{a}}$ correção & 295.161 & 163.620 & 164.200 \\
\hline
\end{tabular}

Tabela 4: Redações do ENEM corrigidas em 2014, 2015 e 2016

Uma última evidência vem do próprio texto dos critérios de correção ${ }^{34}$. Esse texto, a princípio, deveria apresentar uma sequência tipológica injuntiva (prescritiva), apresentando instruções ao alocutário em relação a um procedimento. A linguagem utilizada nessa sequência é menos subjetiva e não se espera a presença de operadores do tipo que utilizamos em nossa análise. Entretanto, essa expectativa não se cumpre. Há várias marcas de subjetividade no texto dos critérios de correção de redação do ENEM. Mendes (2013) mostra que a definição desses critérios envolve valores subjetivos, expressos por modalizadores, vagueza conceitual e termos obscuros. Aplicando a nossa lista de operadores de viés linguístico no texto, que é composto por 640 palavras, observamos 51 ocorrências de operadores argumentativos, o que aponta aproximadamente para $8 \%$, e 12 ocorrências de operadores de opinião e valoração, o que representa aproximadamente $2 \%$ do total de palavras do texto. Não aparecem operadores de pressuposição e de modalidade. Se os próprios critérios que norteiam a correção apresentam alto grau de viés linguístico, não podemos esperar que as correções sejam isentas de viés.

Os nossos resultados, acrescidos das três evidências aqui apresentadas, nos levam a concluir, em concordância com Mendes (2013), que a redação não é um bom instrumento avaliativo quando é imperiosa a isenção.

\section{Considerações finais}

Este artigo teve como principal objetivo demonstrar a subjetividade na correção de redações através da detecção automática de linguagem enviesada. Fizemos uma análise quantitativa de operadores de viés linguístico em textos de correção de redação, coletados no banco de redações do UOL. Assumimos, a partir da Semântica Argumentativa, que há certas palavras e expressões que explicitam pontos de vista e a distribuição numérica desses itens no texto pode indicar graus de subjetividade, o viés

\footnotetext{
${ }^{34}$ Disponíveis em: http://download.inep.gov.br/ educacao_basica/enem/guia_participante/2017/ manual_de_redacao_do_enem_2017.pdf.
} 
linguístico. A partir disso, elaboramos uma lista desses operadores, baseados na classificação encontrada em Koch $(2011,2015)$. Essa lista foi, assim, aplicada ao corpus de correções de redação. Foram também analisados esses operadores de viés linguístico em resumos acadêmicos e em resenhas de produtos publicadas em sites de vendas na internet. Esses resultados numéricos foram comparados aos resultados encontrados para as correções, utilizando como ferramenta estatística o gráfico boxplot. Para essa comparação, partimos do pressuposto de que resumos acadêmicos são menos subjetivos e resenhas são mais subjetivas. Nosso propósito era, assim, verificar de qual polo de subjetividade as correções mais se aproximavam, maior subjetividade ou menor subjetividade.

Considerando a importância da redação em processos seletivos, espera-se que um texto como a correção de uma redação não apresente um alto nível de viés linguístico, aproximando-se do grau de subjetividade encontrado em resumos acadêmicos. Porém, nossa análise apontou para a direção oposta a essa expectativa. A análise quantitativa revela que os textos de correção de redação apresentam um número alto de operadores de viés, quando comparados aos demais gêneros, se aproximando do polo mais subjetivo e, até mesmo, superando os textos desse polo, as resenhas, para alguns operadores. Assim, apontamos como conclusão em nossa pesquisa que há um alto grau de subjetividade na correção de redações. Consideramos que tal resultado não é o desejado para um gênero textual que deveria apresentar um baixo grau de subjetividade, devendo, a princípio, se voltar para os critérios de correção, e não para a opinião do corretor. Ainda, estando nossos resultados de acordo com o que já apontou Mendes (2013), concluímos que os resultados obtidos através da análise do nosso corpus indicam a subjetividade do processo avaliativo como um todo.

\section{Agradecimentos}

Agradecemos ao Prof. Frederico R.B. Cruz (DEST/UFMG) as úteis orientações em relação à análise estatística. Os professores Márcia Cançado, Adriano Veloso e Heliana Mello agradecem o apoio financeiro do CNPq.

\section{Referências}

Aluísio, Sandra, Jorge Pelizzoni, Ana Raquel Marchi, Lucélia de Oliveira, Regiana Manenti \& Vanessa Marquiafável. 2003. An account of the challenge of tagging a reference corpus for brazilian portuguese. Em $6^{\text {th }}$ international conference on Computational processing of the Portuguese language (PROPOR), 110-117.

Aluísio, Sandra Maria \& Gladis Maria de Barcellos Almeida. 2006. O que é e como se constrói um corpus? lições aprendidas na compilação de vários corpora para pesquisa linguística. Calidoscópio 4(3). 156-178.

Anscombre, Jean-Claude \& Oswald Ducrot. 1976. L'argumentation dans la langue. Langages 42. 5-27.

Conrad, Alexander, Janyce Wiebe \& Rebecca Hwa. 2012. Recognizing arguing subjectivity and argument tags. Em Workshop on extrapropositional aspects of meaning in computational linguistics, 80-88.

Damasceno, Adriana Carla, Rafael Andrade, Israel Almeida, Mayrlla Lopes \& Silvana Nóbrega. 2016. Descrevendo o uso dos computadores nas escolas públicas da paraíba. Revista Brasileira de Informática na Educação 24(3). do) 10.5753/rbie.2016.24.3.47.

Ducrot, Oswald. 1987. O dizer e o dito. Pontes Editores.

Fiorin, José Luiz. 2007. A linguagem em uso. Em Ana Scher, Antonio V. Pietroforte, Diana P. Barros, Esmeralda V. Negrão, Evani Viotti, Luiz Tatit, Margarida Petter, Paulo Chagas, Raquel Santos \& Ronald Beline (eds.), Introdução à Linguística, 165-185. São Paulo: Editora Contexto.

Hartmann, Nathan, Lucas Avanço, Pedro Paulo Balage Filho, Magali Sanches Duran, Maria Das Graças Volpe Nunes, Thiago Alexandre Salgueiro Pardo \& Sandra M Aluísio. 2014. A large corpus of product reviews in portuguese: Tackling out-of-vocabulary word. Em International Conference on Language Resources and Evaluation (LREC), 3865-3871.

Hooper, Joan B. 1974. On assertive predicates. Indiana University Linguistics Club.

Japiassú, André Miguel. 2013. Como elaborar e submeter resumos de trabalhos científicos para congressos. Revista Brasileira de Terapia Intensiva 25(2). 77-80. do) $10.5935 / 0103-507 X .20130016$.

Karttunen, Lauri. 1971. Implicative verbs. Language 47(2). 340-358. do) 10.2307/412084.

Kiparsky, Paul \& Carol Kiparsky. 1968. Fact. Linguistics Club, Indiana University. 
Koch, Ingedore Grunfeld Villaça. 2011. Argumentação e linguagem. Cortez Editora 13th edn.

Koch, Ingedore Grunfeld Villaça. 2015. A interação pela linguagem. Editora Contexto 11th edn.

Lane, David M, David Scott, Mikki Hebl, Rudy Guerra, Dan Osherson \& Heidi Zimmer. 2017. Introduction to statistics, online edition. Rice University, University of Houston Clear Lake, and Tufts University.

Levin, Beth \& Malka Rappaport Hovav. 1995. Unaccusativity: At the syntax-lexical semantics interface. MIT press.

Lin, Chenghua, Yulan He \& Richard Everson. 2011. Sentence subjectivity detection with weakly-supervised learning. Em $5^{\text {th }}$ International Joint Conference on Natural Language Processing, 1153-1161.

Lin, Wei-Hao, Theresa Wilson, Janyce Wiebe \& Alexander Hauptmann. 2006. Which side are you on?: identifying perspectives at the document and sentence levels. Em $10^{\text {th }}$ conference on computational natural language learning, 109-116.

Liu, Bing, Minqing Hu \& Junsheng Cheng. 2005. Opinion observer: analyzing and comparing opinions on the web. Em $14^{\text {th }}$ international conference on World Wide Web, 342-351. do) $10.1145 / 1060745.1060797$.

Marcuschi, Luiz Antônio. 2002. Gêneros textuais: definição e funcionalidade. Em Angela Paiva Dionisio; Anna Rachel Machado; Maria Auxiliadora Bezerra (ed.), Gêneros textuais e ensino, 19-36. Lucerna.

Mendes, Eliana Amarante de Mendonça. 2013. A avaliação da produção textual nos vestibulares e outros concursos: a questão da subjetividade. Avaliação: Revista da Avaliação da Educação Superior (Campinas) 18(2). 435458. do) 10.1590/S1414-40772013000200011.

Motta-Roth, Désirée \& Graciela Rabuske Hendges. 2010. Produção textual na universidade. Parábola Editorial.

Pires de Oliveira, Roberta. 2001. Semântica formal: uma breve introdução. Mercado de Letras.

Recasens, Marta, Cristian Danescu-NiculescuMizil \& Dan Jurafsky. 2013. Linguistic models for analyzing and detecting biased language. Em $51^{\text {st }}$ Annual Meeting of the Association for Computational Linguistics, 1650-1659.
Rodrigues, Ricardo, Hugo Gonçalo Oliveira \& Paulo Gomes. 2014. LemPORT: a highaccuracy cross-platform lemmatizer for portuguese. Em $3^{\text {rd }}$ Symposium on Languages, Applications and Technologies, 267-274. do) 10.4230/OASIcs. SLATE. 2014.267.

Sardinha, Tony Berber. 2002. Tamanho de corpus. The Especialist 23(2). 103-122.

Somasundaran, Swapna \& Janyce Wiebe. 2010. Recognizing stances in ideological on-line debates. Em Workshop on Computational Approaches to Analysis and Generation of Emotion in Text, 116-124.

Turney, Peter D. 2002. Thumbs up or thumbs down?: semantic orientation applied to unsupervised classification of reviews. Em $40^{\text {th }}$ Annual Meeting of the Association for Computational Linguistics, 417-424. do) $10.3115 / 1073083.1073153$.

Wiebe, Janyce, Theresa Wilson, Rebecca Bruce, Matthew Bell \& Melanie Martin. 2004. Learning subjective language. Computational linguistics 30(3). 277-308. do) $10.1162 / 0891201041850885$.

Wolcott, Willa \& Sue M Legg. 1998. An overview of writing assessment: Theory, research, and practice. ERIC.

Yano, Tae, Philip Resnik \& Noah A Smith. 2010. Shedding (a thousand points of) light on biased language. Em Workshop on Creating Speech and Language Data with Amazon's Mechanical Turk, 152-158.

Yule, George. 1996. Pragmatics. Oxford University Press. 